\title{
Dermatologic Manifestations In Chronic Kidney Disease Patients On Hemodialysis
}

Shrestha $P^{l}$, Mathur $M^{2}$

${ }^{I}$ Resident, Department of Dermatology \& Venerology, College of Medical Sciences, Bharatpur ${ }^{2}$ Professor, Department of Dermatology \& Venerology, College of Medical Sciences, Bharatpur

\author{
Address for correspondence \\ Dr. Prativa Shrestha, MD \\ Vayodha Hospitals Pvt Ltd, Kathmandu \\ shrestha_prativa@yahoo.com
}

\section{Citation}

Shrestha P, Mathur M. Dermatologic manifestations in chronic kidney disease patients on hemodialysis. NJDVL 2014; 12(1): 34 - 40.

\begin{abstract}
Introduction: Dermatologic changes are frequently seen in chronic kidney disease (CKD) patients. Early identification of these manifestations helps timely institution of treatment and prevention of progression of CKD.
\end{abstract}

Objectives: The aim of this study was to evaluate the frequency and pattern of dermatologic problems among CKD patients who are on maintenance hemodialysis in our population.

Material and Methods: A hospital based cross sectional comparative study was conducted. Fifty patients with CKD on hemodialysis were compared with the same number of non CKD patients. All the patients were clinically examined. Complementary diagnostic measures such as skin biopsy, gram stain, potassium hydroxide mounting and culture sensitivity of the lesions were carried out when necessary.

Results: At least one dermatologic manifestation was present in $86 \%$ of the patients and changes were seen commonly in CKD patients who had GFR $<15 \mathrm{ml} / \mathrm{min}(83.8 \%)$. Cutaneous manifestations were significantly associated with CKD patients than control $(p<0.001)$ but not with the duration of CKD and duration of hemodialysis. Thirty seven patients (74\%) were having cutaneous lesions, commonest being xerosis (52\%) followed by pruritus (40\%) and hyperpigmentation (32\%). Nail, mucous membrane and hair changes were present in $56 \%, 22 \%$ and $12 \%$ respectively, commonest being white nail (30\%), furred tongue (18\%), telogen effluvium $(10 \%)$ respectively.

Conclusion: In our study, dermatologic manifestations were common in CKD patients with GFR $<15 \mathrm{ml} / \mathrm{min}$. Cutaneous and nail changes were seen in $74 \%$ and $56 \%$ of the CKD patients undergoing hemodialysis, commonest changes being xerosis and white nail respectively.

Keywords: Dermatologic manifestations, CKD, Hemodialysis 


\section{Original Article}

\section{Introduction}

A timely recognition of kidney disease at its early stage may prevent progression of acute to chronic and early chronic to end stage renal disease (ESRD). An early identification of dermatologic manifestation could aid in diagnosis of early CKD stages. As reported in literature, $50-100 \%$ of patients have at least one identifiable dermatologic disorder and $41 \%$ have specific manifestations related to the disease. ${ }^{1,2}$ We aimed to identify common dermatologic manifestations in these patients in our population.

\section{Material and Methods}

A hospital based, cross sectional comparative observational study was conducted at Department of Dermatology of College of Medical Sciences (COMS), to identify the pattern of dermatologic manifestations in CKD patients on maintenance hemodialysis attending Renal Unit of COMS between periods October 2009 to April 2011. All cases of CKD were diagnosed according to the criteria of KDOQI CKD Guidelines $2000 .^{3}$ Patients who had renal transplantation and paediatric patients with CKD were excluded. Fifty cases with CKD under hemodialysis meeting the inclusion criteria over a period of 18 months were included. The same number of age, sex, etiology matched individuals without CKD were selected as compare groups randomly from the Medicine out patient department, COMS. An informed consent was received from all the individuals enrolled in this study. All the patients were subjected to routine urine examination, 24hours urine protein, complete hemogram, blood sugar levels (fasting and 2hours postprandial), serum urea, creatinine, calcium, inorganic phosphate, total protein, albumin and chest Xray. Serological test for HIV, Hepatitis B and C were done in all patients. Culture and sensitivity of pus discharge from skin lesion, potassium hydroxide wet mount preparation were performed in suspected cases of bacterial and fungal infections respectively. Skin biopsy for histopathological examinations of skin lesion was performed whenever required. Statistical analysis was performed using computer programme SPSS version 18. Continuous data were demonstrated as mean \pm standard deviation. $\mathrm{P}$ value less than 0.05 was considered statistically significant.

\section{Results}

Among 50 patients there were $29(58 \%)$ males and $21(42 \%)$ females. The age distribution of the patients ranged from $20-86$ years with mean age of $47.66 \pm$ SD 16.40 years and majority of the patients were in the age group of 50-69 years (42\%) (Figure1).

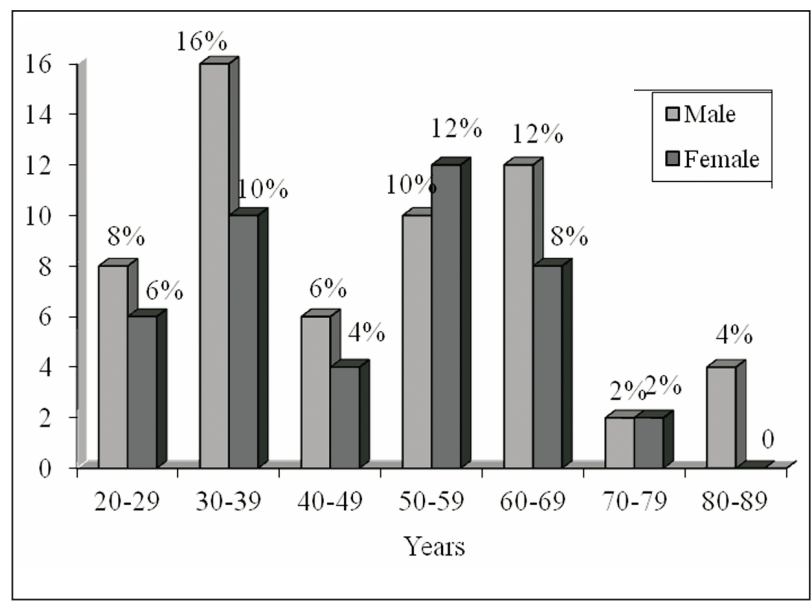

Figure 1: Frequency of chronic kidney disease patients according to age group

Out of 50 participants in compare group, there were 29 (58\%) males and 21 (42\%) females. There were diversity of primary etiologies which led to chronic kidney disease in our patients (Table 1). Hypertension and diabetes mellitus followed by primary glomerulopathies were the most common etiologies leading to $\mathrm{CKD}$ in our patients. None of the patients were positive for hepatitis $B$ virus, hepatitis $C$ virus and human immunodeficiency virus. All patients were receiving at least one medication including iron, vitamins, phosphate binding gels, antihypertensives, diuretics, or insulin etc. 


\section{Original Article}

Table 1: Frequency of etiology leading to chronic kidney disease in our patients

\begin{tabular}{l|c|c|c}
\hline Cause & Male & Female & Total \\
\hline HTN & $8(44.4 \%)$ & $10(55.6 \%)$ & $18(36.0 \%)$ \\
DM & $6(75.0 \%)$ & $2(25.0 \%)$ & $8(16.0 \%)$ \\
HTN \& DM & $3(60.0 \%)$ & $2(40.0 \%)$ & $5(10.0 \%)$ \\
CGN & $2(66.7 \%)$ & $1(33.3 \%)$ & $3(6.0 \%)$ \\
RPGN & $2(100.0 \%)$ & - & $2(4.0 \%)$ \\
Ectopic kidney disease & - & $1(100.0 \%)$ & $1(2 \%)$ \\
Polycystic kidney disease & $1(100.0 \%)$ & - & $1(2.0 \%)$ \\
Malignancy & $1(50.0 \%)$ & $1(50.0 \%)$ & $2(4.0 \%)$ \\
Unknown & $6(60.0 \%)$ & $4(40.0 \%)$ & $10(20.0 \%)$ \\
\hline Total & $29(58.0 \%)$ & $21(42.0 \%)$ & $50(100 \%)$ \\
\hline
\end{tabular}

Duration of kidney disease in our patients ranged from 3 to 60 months with mean duration $15 \pm$ SD 13.61 months. Majority of the patients i.e, 33 $(66 \%)$ had CKD for less than 12 months and 2 (4\%) had CKD for more than 48 months. All patients had undergone hemodialysis for variable period of time. The duration of hemodialysis ranged from 2 weeks ( 0.2 months) to 36 months. Cutaneous manifestations were seen in 37 (74\%) cases compared to only 12 (24\%) controls (Figure 2). The occurrence of cutaneous manifestations were independent of age and gender. The frequency of cutaneous manifestations was higher in those with duration of CKD for less than one year $(p=0.067)$ and with duration of hemodialysis for less than one year $(p=0.645)$ as well as in those with GFR less than $15 \mathrm{ml} / \mathrm{min}(83.8 \%)$ $(\mathrm{p}=0.05)$.

Cutaneous manifestations in our patients was significantly associated with high blood urea level $(p=0.003)$ (Table 2). The pattern of cutaneous manifestations seen were xerosis in $26(52 \%)$, pruritus in $20(40 \%)$, pigmentation in $16(32 \%)$, pallor in $9(18 \%)$, icthyosis in $8(16 \%)$, purpura in $2(4 \%)$, infectious disease in $2(4 \%)$ and others in $6(12 \%)$ of the CKD patients (Table 3$)$. Pruritus was unaffected by rest, activity, cold and dialysis but exacerbated by sleep, dry skin and heat (Table $4 \& 5$ ). No correlation between severity of pruritus and degree of uremia was established $(p=0.418)$. Other cutaneous manifestations observed were seborrhoeic keratosis $(2 \%)$, erythema ab agne $(2 \%)$, cherry angioma (2\%) and bullous lesion (2\%) whose histopathology revealed nonspecific dermatitis.

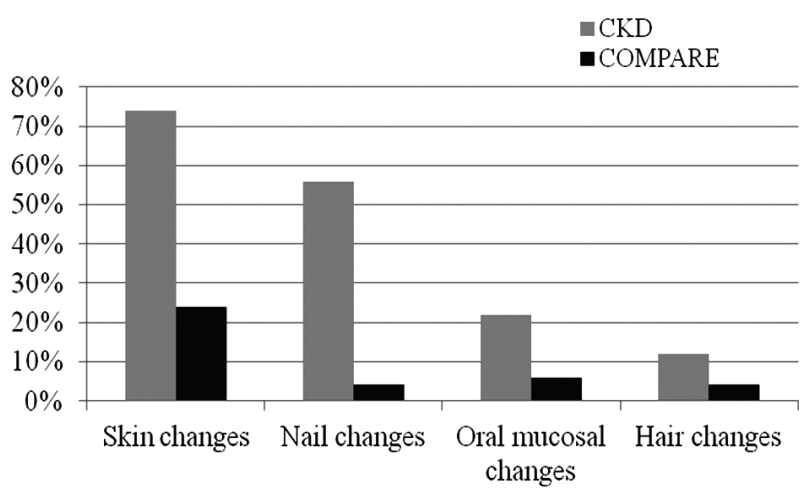

Figure 2: Bar diagram showing comparision of dermatologic manifestations in CKD patients versus compare group. 
Vol. 12, No. 1, 2014

\section{Original Article}

Table 2: Correlation of cutaneous manifestations with different blood investigations in chronic kidney disease patients

\begin{tabular}{|c|c|c|c|c|}
\hline Variables & $\begin{array}{c}\text { Cutaneous } \\
\text { Manifestation }\end{array}$ & Mean & Std. deviation & $\begin{array}{c}\text { P value by } \\
\text { T-test }\end{array}$ \\
\hline \multirow[t]{2}{*}{ Serum Creatinine $(\mathrm{mg} / \mathrm{dl})$} & Present $(n=37)$ & 8.95 & 4.18 & 0.015 \\
\hline & Absent $(n=13)$ & 5.78 & 2.83 & \\
\hline \multirow[t]{2}{*}{ Blood Urea (mg/dl) } & Present $(n=37)$ & 193.80 & 91.58 & 0.003 \\
\hline & Absent $(n=13)$ & 112.35 & 38.56 & \\
\hline \multirow[t]{2}{*}{ Blood sugar Fasting (mg/dl) } & Present $(n=37)$ & 93.45 & 36.04 & 0.377 \\
\hline & Absent $(n=13)$ & 84.18 & 16.51 & \\
\hline \multirow[t]{2}{*}{ Blood sugar Post prandial (mg/dl) } & Present $(n=37)$ & 147.8 & 69.95 & 0.398 \\
\hline & Absent $(n=13)$ & 130.23 & 40.40 & \\
\hline
\end{tabular}

Table 3: Pattern of cutaneous manifestations according to etiology

\begin{tabular}{|c|c|c|c|c|c|c|c|c|}
\hline 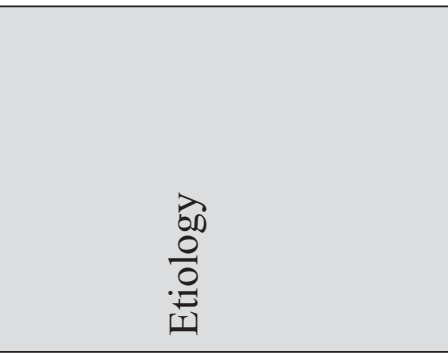 & $\begin{array}{l}\frac{n}{n} \\
0 \\
0 \\
0 \\
x\end{array}$ & 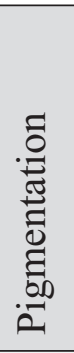 & 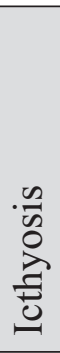 & $\stackrel{\mathscr{E}}{\stackrel{E}{E}}$ & $\stackrel{\overline{0}}{\bar{\sigma}}$ & ص్ & 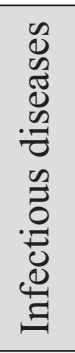 & $\frac{\tilde{\omega}}{\mathbb{0}}$ \\
\hline HTN & 11 & 6 & 3 & 9 & 5 & 1 & 1 & - \\
\hline $\mathrm{DM}$ & 5 & 1 & 3 & 3 & - & - & - & 2 \\
\hline HTN \& DM & 1 & 2 & - & 1 & 2 & - & - & 2 \\
\hline CGN & - & 1 & - & 1 & - & 1 & 1 & - \\
\hline RPGN & 1 & 1 & - & - & 1 & - & - & - \\
\hline Ectopic kidney disease & - & - & - & - & - & - & - & - \\
\hline Polycystic kidney disease & 1 & 1 & - & 1 & - & - & - & - \\
\hline Malignancy & 1 & - & - & 1 & - & - & - & - \\
\hline Unknown & 6 & 4 & 2 & 4 & 1 & - & - & 2 \\
\hline Total & 26 & 16 & 8 & 20 & 9 & 2 & 2 & 6 \\
\hline
\end{tabular}


Original Article

Table 4: Comparison of blood urea with severity of pruritus $(\mathrm{n}=50)$

\begin{tabular}{|c|c|c|c|c|c|}
\hline \multirow[b]{2}{*}{$\begin{array}{l}\text { Blood Urea } \\
\text { levels (mg/dl) }\end{array}$} & \multicolumn{4}{|c|}{ Severity of Pruritus $(\mathrm{p}=0.418)$} & \multirow[b]{2}{*}{ 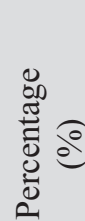 } \\
\hline & $\frac{\partial}{\Sigma}$ & 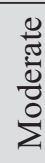 & $\begin{array}{l}0 \\
\stackrel{0}{0} \\
\tilde{D}\end{array}$ & $\begin{array}{l}\tilde{0} \\
z\end{array}$ & \\
\hline$<99$ & - & - & 2 & 8 & $20 \%$ \\
\hline $100-149$ & 4 & - & 2 & 9 & $30 \%$ \\
\hline 150-199 & 1 & 1 & 2 & 5 & $18 \%$ \\
\hline $200-249$ & 1 & - & 1 & 3 & $10 \%$ \\
\hline$>250$ & 2 & 3 & 1 & 5 & $22 \%$ \\
\hline Total & 8 & 4 & 8 & 30 & 100 \\
\hline
\end{tabular}

Table 5: Comparison of factors influencing pruritus $(\mathrm{n}=50)$

\begin{tabular}{l|c|c|c}
\hline Factor & No effect & Exacerbating & Ameliorating \\
\hline Rest & $18(90 \%)$ & $1(5 \%)$ & $1(5 \%)$ \\
Sleep & $5(25 \%)$ & $15(75 \%)$ & - \\
Activity & $19(95 \%)$ & $1(5 \%)$ & - \\
Dry skin & $7(35 \%)$ & $13(65 \%)$ & - \\
Heat & $10(50 \%)$ & $10(50 \%)$ & \\
Cold & $19(95 \%)$ & - & $1(5 \%)$ \\
Dialysis & $12(60 \%)$ & $4(20 \%)$ & $4(20 \%)$ \\
\hline
\end{tabular}

Nail changes were seen in $28(56 \%)$ cases compared to $2(4 \%)$ controls $(\mathrm{p}<0.001)$ (Figure $2)$. The pattern of nail changes seen were white nail in $15(30 \%)$, longitudinal ridges in $13(26 \%)$, onychomycosis in $5(10 \%)$, half and half in 5 (10\%), onycholysis in $3(6 \%)$, subungual hyperkeratosis in $3(6 \%)$, transverse ridging in 2 $(4 \%)$, clubbing in $1(2 \%)$ and pitting in $1(2 \%)$. Majority of the patients (28\%) with white nail had hemoglobin less than $10 \mathrm{gm} / \mathrm{dl}$. Both the controls had longitudinal ridging.

Hair changes were seen in $6(12 \%)$ of cases compared to control 2(4\%) and the difference is not statistically significant $(\mathrm{p}=0.140$ ) (Figure 2 ). Both the controls with hair changes were male; one with diabetes mellitus had telogen effluvium and other with hypertension had androgenetic alopecia. The pattern of hair changes seen in our patients were telogen effluvium $5(62.5 \%)$, lower limb hair loss $2(25 \%)$ and drying with hair fragility $1(12.5 \%)$.

Oral mucosal changes seen in $11(22 \%)$ of cases and $3(6 \%)$ of control (Figure 2), but the difference wasn't statistically significant $(\mathrm{p}=0.021)$. Oral mucosal changes seen were furred tongue in 9 $(75 \%)$, scrotal tongue in $2(16.6 \%)$ and angular cheilitis in $1(8.3 \%)$ of our patients.

\section{Discussion}

In 2009 Nunley et $\mathrm{al}^{1}$ have reported $50-100 \%$ of patients with CKD have at least one cutaneous manifestations and $74 \%$ of patients had at least one cutaneous manifestation in our patients. The occurrence of cutaneous manifestation in our patient was independent of age and gender. Frequency of the cutaneous manifestations in those who had CKD for $<12$ months, 13-24 months and 25-36 months were 50\%, 16\% and $8 \%$ respectively. However this progressive decline in frequency was not statistically significant $(p=0.067)$, as majority $(66 \%)$ of the study patients had CKD for less than 12 months. A study from Nepal has also reported similar findings. ${ }^{4}$ Xerosis, pruritus and hyperpigmentation were the three most common cutaneous manifestations in our patients which is consistent with the findings of other studies by Pico et al, ${ }^{2}$ Amatya et $a 1,{ }^{4}$ Robinson et $\mathrm{al}^{5}{ }^{5}$ Khanna et $\mathrm{al}^{6}$ and Silverberg et $\mathrm{al}^{7}$ (Table 3). Khanna et $\mathrm{al}^{6}$ reported xerosis as the most common cutaneous manifestations (72\%) in their patients. In our study, xerosis was the most frequent cutaneous manifestation (52\%), which was higher than that observed (28\%) by Amatya et al. ${ }^{4}$ In our study there was no correlation between the degree of uremia and the severity of pruritus ( $p=0.418$ ) (Table 4). It is believed that pruritus doesn't result from raised serum urea levels. Various authors have suggested elevated calcium and phosphate levels as contributing factors for the development of pruritus in CRF 


\section{Original Article}

patients. However, no correlation has been reported between pruritus and elevated calcium $(p=0.959)$ and elevated phosphorus level $(p=0.595)$ in our study. Also Amatya et $\mathrm{al}^{4}$ and Khanna et $\mathrm{al}^{6}$ did not show any relation between pruritus and serum calcium and phosphate. Positive correlation between xerosis and pruritus was suggested by Khanna et $\mathrm{al}^{6}$ and reported $87 \%$ of their patients with pruritus had xerosis. Similarly in our study $75 \%$ of patients with pruritus had xerosis. Exacerbation of pruritus with dry skin was reported by $13(65 \%)$ patients. Morton et $\mathrm{al}^{8}$ revealed lower hydration of stratum corneum in uremic patients with pruritus and dry skin promotes sensation of itch by lowering the threshold for itch. In our study majority i.e, 15 (75\%) of patients with pruritus reported exacerbation during sleep. However, majority of the patients with pruritus $18(90 \%)$ reported no change during rest at daytime and only $1(5 \%)$ reported its exacerbation during rest (Table 5). Our findings was in agreement with Zucker et $\mathrm{al}^{9}$ study, who reported pruritus was not evenly distributed over the day, rather it occurred more often and with greater intensity at night. The probable cause of worsening of pruritus at night is at least in part by physiologic changes with diurnal rhythm, which could be related to expression of circardian rhythms of peptides and their receptors in neurons. ${ }^{10}$

In our study cutaneous pigmentation was present in $16(32 \%)$ of the patients, out of which $11(22 \%)$ had diffuse pigmentation over the sun exposed areas and 5(10\%) had generalized pigmentation (Table 5). Khanna et $\mathrm{al}^{6}$ suggested that increased prevalence of diffuse hyperpigmentation predominantly over photo-exposed sites with sparing of sun protected sites could be due to tropical climate and sun exposure.

Silverberg et $\mathrm{al}^{7}$ reported infectious cutaenous lesions in $70 \%$ of their patients with CRF, the most common being verrucae vulgaris, pityriasis versicolor, folliculitis and herpes zoster. In this study only 2 (4\%) had infectious cutaneous lesions, one had pityriasis versicolor with folliculitis and other had herpes simplex labialis, which was lower than seen in other studies . Similarly Amatya et $\mathrm{al}^{4}$ from Nepal also reported only 5 infectious cutaneous lesions out of 104 cases. Metastatic calcification, APD and NFD were not present in any of our patient. Similarly metastatic calcification, bullous dermatosis and APD were absent in a study by Hajheydari et al. $^{11}$

White nail (30\%), longitudinal ridges (26\%) and onychomycosis $(10 \%)$ were the common nail changes in our study. Amatya et al reported white nail in $62 \%$ and half and half in $4 \%$ of their patients. ${ }^{4}$ Pico et $\mathrm{al}^{2}$ have found half and half in $40 \%$, leukonychia in $20 \%$ of CRF patients and reported that half and half nails increases in prevalence with respect to time of dialysis and was significantly associated with hemodialysis. All the CKD patients in our study had undergone hemodialysis but the number of patients on hemodialysis for prolonged duration was small $(14 \%)$ and may explain the reason of low prevalence of half and half nails. In our study majority $(28 \%)$ of the patients with white nail had hemoglobin less than $10 \mathrm{gm} / \mathrm{dl}$ which implicate it as a non specific sign of anaemia.

In our study oral mucosal changes observed in $22 \%$ cases, similarly reported in $24 \%$ by Hajheydari et al. ${ }^{11}$ The pattern of oral mucosal changes seen in our patients were furred tongue in $9(75 \%)$, scrotal tongue in $2(16.6 \%)$ and angular chelitis in $1(8.3 \%)$.

Hair changes observed in our patients was 6 $(12 \%)$ in compare to $2(4 \%)$ in control, however the difference is not statistically significant $(p=$ 0.140 ). The pattern of hair changes seen in our patients were telogen effluvium $5(62.5 \%)$, non scarring lower limb hair loss $2(25 \%)$ and drying with hair fragility $1(12.5 \%)$. Hajheydari et al ${ }^{11}$ reported more than half of the patients in their 


\section{Original Article}

study had at least 1 hair disorder, the most common of which were scalp hair loss (10\%) and disseminated hair loss of the entire body, particularly of the lower limbs (9\%). Kint et $\mathrm{al}^{12}$ and Khanna et $\mathrm{al}^{6}$ reported diffuse alopecia resulting from telogen effluvium was due to heparin use in hemodialysed patients. Therefore non scarring alopecia and or telogen effluvium may be a part of disease or heparin induce.

\section{Conclusion}

At least one dermatologic manifestation was

\section{References}

1. Nunley JR. Dermatologic manifestations of renal disease. Online January, 2009. Available from: http://emedicine.medscape.com/article/109484overview.

2. Pico MR, Somolinos AL, Sanchez JL, Calderon RB. Cutaneous alterations in patients with chronic renal failure. Int J Dermatol 1992; 31: 860-3.

3. National Kidney Foundation KDOQI Clinical Practice Guidelines for Chronic Kidney Disease: Evaluation, Classification, and Stratification. Am J Kidney Disease 2002; 34: S1-266.

4. Amatya B, Agrawal S, Dhali T, Sharma S, Pandey SS. Pattern of skin and nail changes in chronic renal failure in Nepal: A hospital based study. J Dermatol 2008; 35: 140-5.

5. Robinson-Bostom L, DiGiovanna JJ. Cutaneous manifestations of end-stage renal disease. J Am Acad Dermatol 2000; 43: 975-90.

6. Khanna D, Singal A, Kalra OP. Comparision of cutaenous manifestations in chronic kidney disease with or without dialysis. Postgrad Med J 2010; 86: 641-7. present in $86 \%$ of our patients. Presence of any such dermatologic manifestation in the absence of primary dermatological problem warrants a thorough search to rule out kidney disease. Likewise, a detailed cutaneous examination in all patients with renal dysfunction is essential.

Acknowledgement: We would like to extend our gratitude to the entire team of Nephrology Department and Medicine Department of the College of Medical Sciences, Chitwan.

7. Silverberg NB, Singh A, Laude TA. Cutaneous manifestations of chronic renal failure in children of color. Pediatr Dermatol 2001; 18: 199-204.

8. Morton CA, Lafferty M, Hau C, Henderson I, Jones M, Lowe JG. Pruritus and skin hydration during dialysis. Nephron Dial Transplant 1996; 11: 2031-6.

9. Zucker I, Yosipovitch G, David M, Gafter U, Boner G. Prevalence and characterization of uremic pruritus in patients undergoing hemodialysis: uremic pruritus is still a major problem for patients with end stage renal disease. J Am Acad Dermatol 2003; 49: 842-6.

10. Bergasa NV, Link MJ, Keogh M et al. Pilot study of bright-light therapy reflected toward the eyes for the pruritus of chronic liver disease. Am J Gastroenterol 2001; 96: 1563-70.

11. Hajheydari Z, Makhlough A. Cutaneous and mucosal manifestations in patients on maintenance hemodialysis. Iran J Kidney Dis 2008; 2: 86-90.

12. Kint A, Bussels L, Fernandes M, Ringoir S. Skin and nail disorders in relation to chronic renal failure. Acta Derm Venereol 1974; 54: 137. 